\title{
Effect of different combinations of surface treatment on adhesion of resin composite to zirconia
}

This article was published in the following Dove Press journal: Clinical, Cosmetic and Investigational Dentistry

\section{Jihad Saade ' \\ Hasan Skienhe ${ }^{2}$ \\ Hani Ounsi ${ }^{3}$ \\ Jukka P Matinlinna ${ }^{4}$ \\ Ziad Salameh ${ }^{5}$ \\ 'Faculty of Dental Medicine, Lebanese University, Beirut, Lebanon; ${ }^{2}$ Department of Prosthodontics, Faculty of Dental Medicine, Lebanese University, Beirut, Lebanon; ${ }^{3}$ Department of Restorative Dentistry and Endodontics, Faculty of Dental Medicine, Lebanese University, Beirut, Lebanon; ${ }^{4}$ Dental Materials Science, Faculty of Dentistry, University of Hong Kong, Sai Ying Pun, Hong Kong; ${ }^{5}$ Research Center, Faculty of Dental Medicine, Lebanese University, Beirut, Lebanon}

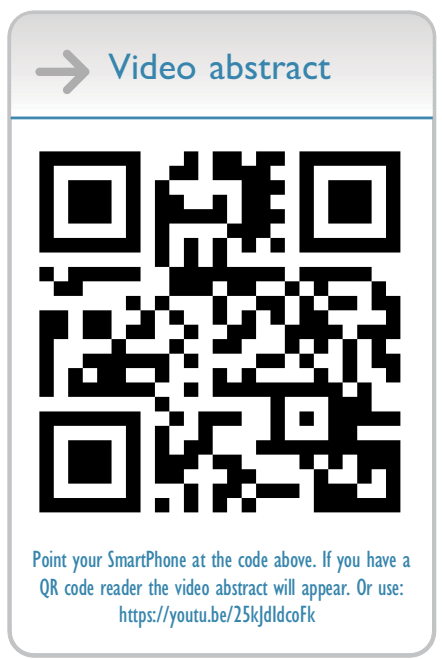

Correspondence: Jihad Saade Faculty of Dental Medicine, Lebanese University, Beirut, Lebanon

Tel +96I 3763404

Email jihadsaade00@gmail.com
Purpose: The purpose of this laboratory study was to evaluate the effect of different surface treatment combinations on resin zirconia bonding.

Materials and methods: One hundred and five pre-sintered zirconia quadrangles were prepared out of zirconia blocks, polished, then sintered and divided into five groups $(n=21)$. Group I (control): samples were untreated, group II: grit-blasting with $50 \mu \mathrm{m}$ alumina particles, group III: grit-blasting with $100 \mu \mathrm{m}$ alumina particles, group IV: Er,Cr:YSGG laser, and group V: selective infiltration etching technique. Microstructural analysis was performed using scanning electron microscopy, atomic force microscopy, a diffractometer, and a profilometer. Cylinders of composite resin were luted with Panavia resin composite cementand Clearfil ceramic primer. Shear bond strength (SBS) was determined using a universal testing machine.

Results: SBS results were analyzed using one-way ANOVA followed by Tukey post hoc tests for multiple comparisons. The level of significance was set to 0.05 . SBS values of the studied groups II, III, IV, and V were $16.2 \pm 1.8 \mathrm{MPa}, 15.7 \pm 3.7 \mathrm{MPa}, 14.8 \pm 3.4 \mathrm{MPa}$, and 16.8 $\pm 3.0 \mathrm{MPa}$, respectively. All values were significantly higher than the control group (10.48 $\pm 1.80 \mathrm{MPa}$ ), but without a significant difference between them. Group III exhibited the roughest surface, and Group I had a more significantly reduced surface roughness value than any other group. Group III presented the highest significant increase of tetragonal to monoclinic phase transformation (13\%).

Conclusion: The use of grit-blasting with greater particles size enhanced SBS with resin composite cement, but induced a higher amount of monoclinic phase transformation. The use of primer based on adhesive monomer with the resin cement is required to enhance the bonding efficiency. The use of laser enhanced the surface roughness and the bonding ability to zirconia.

Keywords: air abrasion, laser, MDP primer, resin cement

\section{Introduction}

The development of computer aided design and computer aided manufacturing (CAD-CAM) technology in dentistry has led to the introduction of a new generation of all ceramic materials such as zirconia. Zirconia still remains one of the mostly used materials using this technology. It is a polymorphic ceramic material, and it has three crystallographic forms: monoclinic (M), from room temperature to $1,170^{\circ} \mathrm{C}$; tetragonal $(\mathrm{T})$, from $1,170^{\circ} \mathrm{C}$ to $2,370^{\circ} \mathrm{C}$; and cubic $(\mathrm{C})$, from $2,370^{\circ} \mathrm{C}$ to the melting point. ${ }^{1,2}$ The high strength, biocompatibility, and esthetic properties of zirconia make it the best substitute to porcelain fused to metal restoration. ${ }^{3}$ 
Since the mid-1990s, several surface conditioning methods and protocols have been developed to enhance the bonding ability to zirconia ceramics. At large, adhesion is based on the micro-mechanical interlocking by using subtractive or additive techniques (coatings) and chemical activation of the surface by adhesive monomers. ${ }^{4}$ Among the most reported surface treatment in the literature are air abrasion with alumina particles, selective infiltration etching, ${ }^{5}$ laser treatment, ${ }^{6}$ tribochemical silica-coating, ${ }^{7}$ and some other silica-coating methods. ${ }^{8}$ Silica-coating is necessary because the glass-free structural composition of zirconia surface makes it resistant to normal clinical etching using the conventional hydrofluoric acid, HF, used with glass ceramic. ${ }^{9,10}$

The regular zirconia surface pretreatment method used in dental laboratories is grit-blasting with alumina particles of an average size of $50 \mu \mathrm{m}$ or $110 \mu \mathrm{m}$. Numerous studies have suggested high bond (adhesion) strength values after grit-blasting in combination with primers or cement that are based on some adhesive monomers. ${ }^{11}$ The most common adhesive monomers that create a chemical bond to the oxide layer are: phosphate ester monomer 10-methacryloyloxydecyl dihydrogenphosphate (10-MDP), 4methacryloxyethyl trimellitic anhydride (4-META), and thiophosphoric acid methacrylate (MEPS). ${ }^{12,13}$

Artificial aging is one of the most important factors for simulating the estimated clinical performance of a restoration since mechanical stresses, temperature, and humid environment can influence the degradation of bonding to zirconia. ${ }^{14,15}$

Aurelio et al concluded that grit blasting improved the flexural strength of zirconia, regardless of the presence or absence of aging. ${ }^{16}$ Amaral et al showed that the increase of flexural strength is due to the toughening mechanism, ${ }^{17}$ and other studies stated that the formation of a protective compression layer on the zirconia surface may decrease the detrimental effects of aging on the specimens. ${ }^{18,19}$

However, grit-blasting subjected the zirconia surface to high stress that led to crack growth. ${ }^{20}$ This could affect the strength and impair the long-term clinical success of zirconia when exposed to the humid environment and mechanical stresses in the oral cavity. ${ }^{21}$

The use of laser energy for the zirconia surface treatment is of interest and has been reported in several studies. Results have shown that a Nd:YAG laser increased the surface roughness and wettability and bond strength to resin cement. ${ }^{22,23}$

Some studies have shown a variability of results that could be due to the laser type and different parameters used for surface treatments. ${ }^{24}$
In spite of this disparity, the use of a Er,Cr; YSGG laser could be an alternative zirconia surface treatment technique to the other methods conventionally used.

The aim of this laboratory study was to evaluate different zirconia surface treatments and their effect on the surface morphology and bond strength of the adhesive system used with zirconia.

The hypotheses tested were: 1) that the different surface treatments evaluated on the zirconia surface would not significantly increase the shear bond strength between zirconia and resin cement; and 2) that the abrasive particles, laser treatment, and selective infiltration etching would not affect the surface morphology, surface roughness, or phase transformation of zirconia.

\section{Materials and methods}

\section{Samples preparation}

One hundred and five quadrangles shaped specimens of presintered 3mol\% yttria-stabilized zirconia (Amman Girrbach, Koblach, Austria) were prepared using a 5-axis-milling device (Ceramill 2, Amman Girrbach, Koblach, Austria) and a low-speed diamond disc (Buehler, Lake Buff, WI, USA). Each specimen was $3 \mathrm{~mm}$ high, $10 \mathrm{~mm}$ wide, and $10 \mathrm{~mm}$ long. Specimens were polished with silicon carbide grit paper $\neq 400$ (Grit flex, Italy) for surface standardization, ${ }^{25}$ and they were then subjected to oil free high pressure airflow for 1 minute. Specimens were then sintered in a sintering furnace (Amman Girrbach, Ceramil therm, Austria) at a heat rate of $10^{\circ} \mathrm{C} / \mathrm{min}$ to the final temperature $1,450^{\circ} \mathrm{C}$ with a 120 minute holding time.

\section{Surface treatment protocols}

Specimens were randomly divided into five study groups $(\mathrm{n}=21)$ according to the surface treatment performed (Table 1):

Group I: (Control) as sintered.

Group II: The surface of sintered Specimens was gritblasted with $50 \mu \mathrm{m} \mathrm{Al}_{2} \mathrm{O}_{3}$ particles (Vacumat 300, Vita Zahnfabrik, Germany) for 15 seconds under 3.5 bars pressure at a working distance of $10 \mathrm{~mm}$ evenly.

Group III: The surface sintered specimens were grit-blasted with $100 \mu \mathrm{m} \mathrm{Al} \mathrm{O}_{3}$ particles for $15 \mathrm{sec}-$ onds and under 3.5 bar pressure at a working distance of $10 \mathrm{~mm}$.

Group IV: The zirconia surface was treated by a laser (Er, Cr: YSGG laser, Water lase MD system, 
Table I Surface treatments protocols

\begin{tabular}{|c|c|c|}
\hline Group & Description & Surface treatment protocols \\
\hline $\mathbf{I}$ & Control & As sintered. \\
\hline II & $50 \mu \mathrm{m} \mathrm{Al}_{2} \mathrm{O}_{3}$ & Grit-blasted with $50 \mu \mathrm{m}$ alumina particles for 15 seconds under 3.5 bars pressure at a working distance of $10 \mathrm{~mm}$. \\
\hline III & $100 \mu \mathrm{m} \mathrm{Al}{ }_{2} \mathrm{O}_{3}$ & Grit-blasted with $100 \mu \mathrm{m}$ alumina particles for 15 seconds under 3.5 bars pressure at a working distance of $10 \mathrm{~mm}$. \\
\hline IV & Er,Cr:YSGG laser & $\mathrm{Er}, \mathrm{Cr}$ :YSGG laser, for 2 minutes at a power of $5.5 \mathrm{~W}, 20 \mathrm{~Hz}$ with $100 \mathrm{~mJ}$ energy. \\
\hline $\mathbf{v}$ & $\begin{array}{l}\text { Selective infiltration } \\
\text { etching }\end{array}$ & $\begin{array}{l}\text { Grit papers } \neq 200-800, \text { a thin layer of low-fusing melting glass was applied on the zirconia surface. The samples } \\
\text { were then heated to } 750^{\circ} \mathrm{C} \text { for } 2 \text { minutes, cooled to } 650^{\circ} \mathrm{C} \text { for I minute, reheated to } 750^{\circ} \mathrm{C} \text { for an additional I } \\
\text { minute, and then cooled to room temperature. The specimens were then immersed in a bath of } 9 \% \text { hydrofluoric } \\
\text { acid for } 20 \text { minutes. }\end{array}$ \\
\hline
\end{tabular}

Biolase, San Clemente, CA, USA) for 2 minutes. A custom-made computerized robot was used to standardize the application of laser and exclude the human factor. The laser was set at a power of $5.5 \mathrm{~W}, 20 \mathrm{~Hz}$ with $100 \mathrm{~mJ}$ energy, ${ }^{26}$ and the surface area which was illuminated by the laser is $64 \mathrm{~mm}^{2}$

Group V: The specimen's surfaces of this group were subjected to a selective infiltration etching (SIE) technique (5). After sintering, the surfaces of the specimens were abraded by a sequence of grit papers $\neq 200$ 800. A thin layer of low fusing melting glass was applied on the zirconia surface. The specimens were then heated to $750^{\circ} \mathrm{C}$ for 2 minutes, cooled to $650^{\circ} \mathrm{C}$ for 1 minute, reheated to $750^{\circ} \mathrm{C}$ for an additional 1 minute, and then cooled to room temperature. The specimens were immersed in a bath of $9 \%$ hydrofluoric acid for 20 minutes, and then every specimen was subjected to a high stream of air and water for 2 minutes.

All specimens were cleaned using an ultrasonic bath of isopropanol for 10 minutes and left to dry at room temperature for 24 hours before bonding. Fifty-five specimens were used for microstructural analysis, and the remaining were used for shear bond testing.

\section{Microstructural analysis $X$-ray diffraction analysis}

Fifteen specimens were used for XRD analysis, three specimens for each group. The surface of the specimens was evaluated using an XRD device (D8 Focus, Bruker ASX, Karlsruhe, Germany). The surfaces were scanned from 5 to 80 using a $2 \theta$ diffractometer and copper $\mathrm{X}$-unit $\left(\mathrm{Cu}-\mathrm{K} \alpha\right.$ radiation) $0.02^{\circ}$ step scan, at a 2 second step interval. X-ray diffraction was used to determine phase composition. The calculation of monoclinic phase fraction (Xm) was based on Gravies and
Nicholson's ${ }^{27}$ method, using the maximum intensities of the reflections:

$$
\begin{aligned}
\mathrm{Xm} & =\mathrm{I}_{\mathrm{m}}(-111)+\mathrm{I}_{\mathrm{m}}(111) / \mathrm{I}_{\mathrm{m}}(-111)+\mathrm{I}_{\mathrm{m}}(111) \\
& +\mathrm{I}_{\mathrm{t}}(111)
\end{aligned}
$$

where $\mathrm{Xm}$ is the mass fraction of monoclinic phase, $\mathrm{I}_{\mathrm{m}}$ $(-111)$ and $I_{m}(111)$ are the intensities of monoclinic peak at 282 theta and 312 theta, $I_{t}(111)$ is the intensity of tetragonal peak at $30^{\circ} 2$ theta. The monoclinic phase volume percentage $(\mathrm{Vm})$ was calculated using a formula by Toraya et $\mathrm{al}:{ }^{28}$

$$
\mathrm{Vm}=1.311 \mathrm{Xm} /(1+0.311 \mathrm{Xm})
$$

Crystallite size analysis was calculated using the peak broadening of XRD reflection of $\mathrm{t}(111)$ at $30^{\circ} 2$ theta using the following formula: ${ }^{29}$

$$
\mathrm{Xs}=0.9 \lambda /(\mathrm{FWHM} \times \cos \theta)
$$

Where $\mathrm{Xs}$ is the crystallite size in nanometers; $\lambda$ is the wavelength of the X-ray beam in nanometers $(\lambda=0.15,406$ $\mathrm{nm}$ for standard detectors), and FWHM is the full width at half maximum height.

\section{Atomic force microscopy}

A total of 10 specimens, two for each group, were used for surface analysis using an atomic force microscope (Agilent 5420 SPM/AFM, Agilent Technologies, Santa Clara, CA, USA). Analysis was performed in contact mode to detect and observe morphological changes on the zirconia surface due to the different surface treatment methods.

\section{Profilometer}

A total of 15 specimens were used for surface roughness (Ra) analysis using a Profilometer (Dailyaid DR 300, Beijing, China). Three specimens for each group were 
used. Four lines were drawn on each specimen with a space of $1.5 \mathrm{~mm}$ between them.

The stylus probe with diamond, 90 cone angle, and 5 $\mu \mathrm{m}$ tip radius passed along the lines with a traveling distance of $2.5 \mathrm{~mm}$ and a sliding speed of $0.135 \mathrm{~mm} / \mathrm{s}$. Each specimen was measured four times, and the mean value was calculated.

\section{Scanning electron microscopy (SEM) and surface elemental analysis (EDX)}

Three specimens from each group were gold sputtered (Sputter Coater 108 Auto, Cressington Scientific Instruments, Watford, UK) and examined using SEM (AIS2100C, SeronTechnologies, ASI2100, Gyeonggi-Do, Korea) at 1000x to 3000x magnification and $20 \mathrm{kV}$. EDX analysis was also performed (AMETEK with EDAX detector). The same specimens were used for EDX analysis.

\section{Shear bond strength of resin cement}

A total of 50 composite (Filtek Z 250, 3M ESPE) cylinders (4 $\mathrm{mm}$ diameter and $4 \mathrm{~mm}$ height) were constructed using a Plexiglas mold. One drop of primer (Clearfil ceramic primer; Kuraray Dental, Tokyo, Japan) was applied onto the zirconia surface with a disposable micro brush, dispersed by airflow for $3 \mathrm{sec}-$ onds and left to react for 20 seconds. The cement (Panavia F2.0; Kuraray Dental) applied through the mixing tip onto the primed surface and the prepared composite cylinders were bonded under a fixed load of $450 \mathrm{~g}$. The excess cement was removed by a curette and micro brush. The bonded samples were cured using a light curing machine (Elipar Free Light 2 LED, 3MEspe, wave length $=430-480 \mathrm{~nm}$, light intensity $=1,000$ $\mathrm{Mw} / \mathrm{cm}^{2}$, Saint Paul, MN, USA). Curing was done at the interface area for 40 seconds from three different directions. The bonded specimens were stored in distilled water for 24 hours at $37^{\circ} \mathrm{C}$.

A shear bond test was conducted to evaluate the bond interface using a Universal testing machine (YL-UTM Main, YLE GmBH). A uni-bevel semi-circle chisel-shaped indenter was used to direct the shear force as close to the zirconia composite interface at a crosshead speed of $1 \mathrm{~mm} /$ minute until failure occurred. The load was recorded in Newtons and converted to MPa by dividing it by the surface area.

\section{Statistical analysis}

The data were analyzed using a statistical software package (SPSS version 23, Armonk, NY, USA). Normality distribution of the specimens for the shear bond groups was done using Kolmogorov-Smirnov test, which showed that the data followed a normally distribution $(P>0.05)$. One-way analysis of variance (ANOVA) was conducted to evaluate the null hypothesis (SBS), followed by the Tukey post hoc tests for multiple comparisons. The level of significance was set to $P \leq 0.05$. The statistical difference between groups (phase transformation, crystallite size, and surface roughness) was tested using nonparametric statistics, as the measured quantitative variable isn't normally distributed. Kruskal-Wallis test was used to compare between more than two groups and the Mann Whitney test to compare between each two groups. $P$-values $\leq 0.05$ were considered statistically significant.

\section{Results}

\section{X-ray diffraction analysis}

The mean value of $\mathrm{Xm} \%$ of all groups is reported in Table 2. All groups reported a significant difference with the control group. The highest significant $\mathrm{Xm}$ value was reported in Group III (13\%), followed by Groups II (8\%), IV (4\%), and V (3\%). The lowest Xm value was for the control group (Table 2).

The mean crystallite size of the control group was 30.7 $\mathrm{nm}$. Groups II and III showed a significant decrease in the crystallite size with all other groups. Group III showed a lower significant decrease in crystallite size when compared to group II (Table 2).

The XRD analysis of groups II and III showed asymmetrical broadening and decreased intensities of $t$ (111) peaks, and reversed intensities of the tetragonal doublets at $\mathrm{t}$ (002) and t (200) (Figure 1).

\section{Surface roughness}

Table 2 shows the surface roughness values of the studied groups. The $R_{a}$ value (in $\mu \mathrm{m}$ ) was chosen as a surface roughness indicator. The lower mean $R_{a}$ value was for the control group $\mathrm{V}(1.84 \mu \mathrm{m})$ with lower significance with Groups, II, III, IV, and V. No statistically significant difference exists between Groups, II, III, IV, and V. 
Table 2 Mean values (SD) of shear bond strength, surface roughness, and mass fraction of monoclinic phase, crystallite size, and full width at half maximum

\begin{tabular}{|c|c|c|c|c|c|}
\hline Groups & $\begin{array}{l}\text { Shear bond strength, } \\
\text { MPa }\end{array}$ & $\begin{array}{l}\text { Surface roughness, } \\
\text { Ra } \mu \mathrm{m}\end{array}$ & $\mathbf{X m} \%$ & AV Crystallite size, $\mathrm{nm}$ t(l0I) & $\begin{array}{l}\text { FWHM, } \\
\text { t(IOI) }\end{array}$ \\
\hline I & $10.48^{11, I 1, I V, V} \pm 1.80$ & $\mathrm{I} .84^{11, \mathrm{III}, \mathrm{IV}, \mathrm{V}} \pm 0.19$ & $0^{11, \mathrm{III,IV}}$ & $30.40^{11, I I I} \pm 0.01$ & 0.28 \\
\hline II & $|6.2|^{\prime} \pm 3.70$ & $4.26^{1} \pm 0.79$ & $8.00^{1, I I I, I V, V} \pm 0.01$ & $19.28^{1, I I I, I V, V} \pm 0.01$ & 0.46 \\
\hline III & $15.70^{1} \pm 2.90$ & $5.12^{1} \pm 0.22$ & $13.00^{\mathrm{l}, \mathrm{II}, \mathrm{IV}, \mathrm{V}} \pm 0.02$ & $12.52^{1, \mathrm{II}, \mathrm{IV}, \mathrm{V}} \pm 0.02$ & 0.67 \\
\hline IV & $14.80^{1} \pm 3.40$ & $4.8 I^{\prime} \pm 0.28$ & $4.00^{1,11,1111} \pm 0.01$ & $34.90^{11,1111} \pm 0.07$ & 0.26 \\
\hline V & $16.80^{1} \pm 3.00$ & $5.02^{1} \pm 0.42$ & $3.00^{1,11, I I I} \pm 0.01$ & $29.50^{11, I I I} \pm 0.01$ & 0.37 \\
\hline
\end{tabular}

Note: Similar superscripts (I-V) indicate significant differences.

Abbreviation: FWHM, full width at half maximum height.

\section{Scanning electron microscopy, surface elemental analysis, and atomic force microscopy}

SEM images of group III show a surface with larger pits and grooves and sharp edges, whereas these grooves are smaller in Group II, but also with sharp edges. Scratches as a result of grit paper polishing appeared in Groups I and V. The difference in the surface texture between the control groupand Group IV is not obvious (Figure 2). Impacted alumina particles appeared in Groups II and III, but with a higher percentage in Group II, as shown in the EDX analysis (Figure 3).

AFM images of Groups II and III show a destructive surface with small grain and barely visible grain boundary, whereas the surface of the control group and Group V appeared with larger and clear grain boundaries. An AFM image of Group IV shows some areas with destructive grains similar to Group II, and other areas with intact texture similar to the control group (Figure 4).

\section{Shear bond test}

The mean value of shear bond strength of the tested groups is shown in Table 2.

Group V shows the highest shear bond value, followed by Groups II, III, and IV. All groups showed a higher significant shear bond value than the control, but no significant difference exists between them.

\section{Discussion}

The results of this laboratory study led to the rejection of the hypothesis tested that the extent of tetragonal to monoclinic phase transformation, surface roughness, and bond strength showed a difference with different surface treatments performed.

Grit-blasting has been reported to be a prerequisite for improving surface roughness and to create a micromechanical bonding area for resin cement. ${ }^{30,31}$ Many studies ${ }^{32,33}$ have stated that the $\mathrm{t}-\mathrm{m}$ phase transformation is increased with the increase of particle size. Hallmann et $\mathrm{al}^{34}$ concluded that there was a $6.75 \% \mathrm{t}-\mathrm{m}$ phase transformation for zirconia abraded with $110 \mu \mathrm{m}$ alumina particles under 3.5 bar pressure, and, on the other hand, $4.72 \%$ for zirconia abraded with $50 \mu \mathrm{m}$ under the same pressure.

The results of the present study suggest that the increase in abrasive particle size is directly related to $\mathrm{t}-\mathrm{m}$ phase transformation, since $50 \mu \mathrm{m}$ and $110 \mu \mathrm{m}$ abrasive particles induced $8 \%$ and $13 \% \mathrm{t}-\mathrm{m}$ phase transformation, respectively, with a significant difference between them and with the control group. The present results are in accordance with many reported studies ${ }^{11,14,20}$ that concluded that the Xm percentage is increased with larger particle size.

On the contrary, Chintapalli et a ${ }^{35}$ found that $12 \%$ and $15 \%$ monoclinic phases were found following sandblasting, irrespective of the size and pressure, and the changes in size and pressure have little effect on the phase transformation due to erosion of the material as well, Özcan et $\mathrm{al}^{36}$ suggested that the increase in $\mathrm{t}-\mathrm{m}$ is not related to the increase in particle size

The Er,Cr;YSGG laser is a useful tool because it increases zirconia surface roughness and, thus, enhances the wettability for better adhesion to resin cement. ${ }^{37}$ It was used with a different power setting without graphite coating to minimize the absorption energy in order to achieve a rough zirconia surface free of crack and with minimum t$\mathrm{m}$ phase transformation. The use of laser application to all samples was standardized by using a custom-made computerized robot to avoid human error during the irradiation. ${ }^{25}$

SEM observations of Group IV showed a non-destructive, non-smooth surface that is free of cracks, but the grains in small areas were melted due to the effect of laser ablation. 

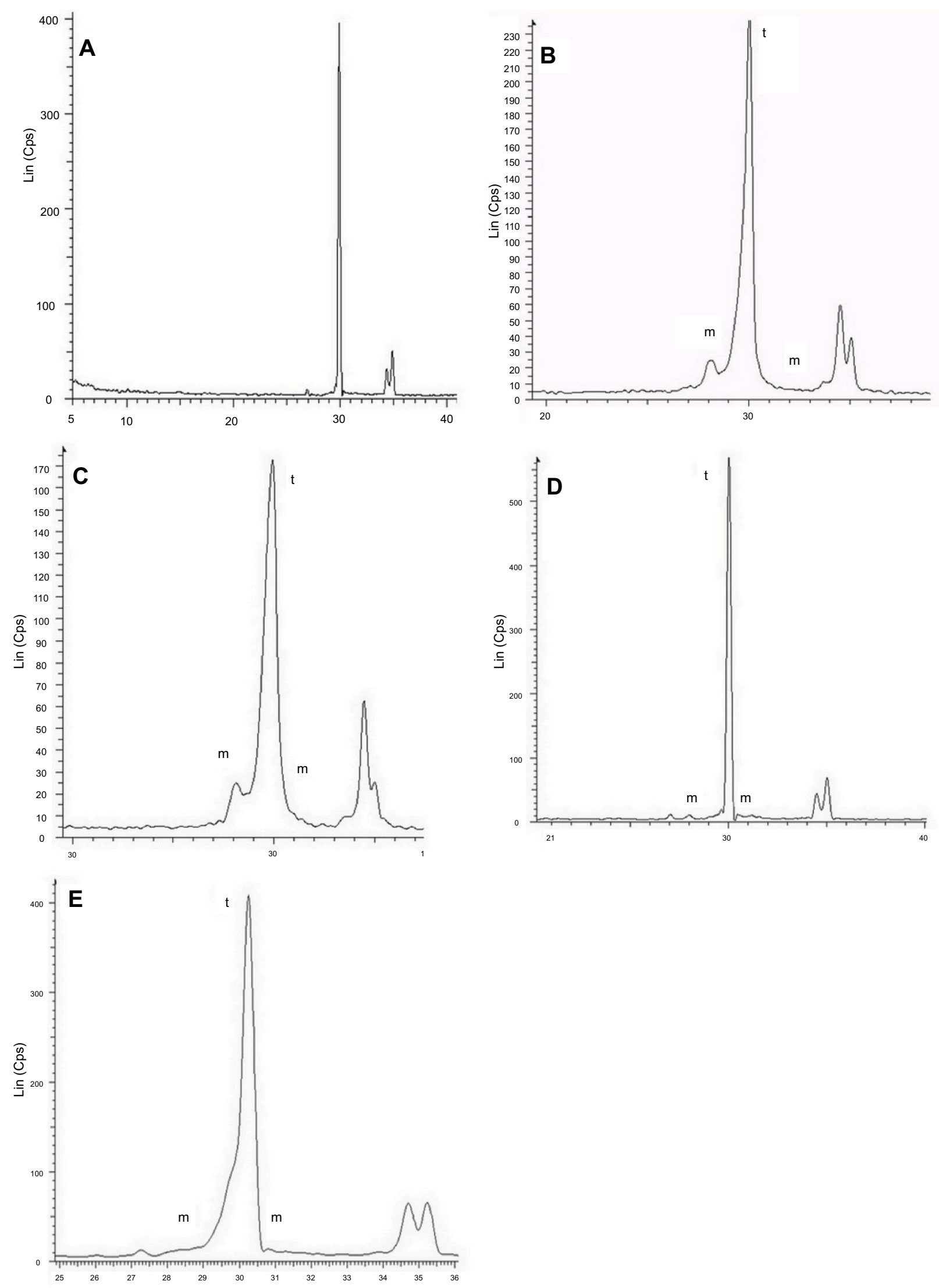

Figure I XRD analysis of Groups I (A), II (B), III (C), IV (D), and V (E). Groups II and III show humps on the left shoulder, decreased intensities and asymmetrical broadening of the t (III) peaks, as well as reversed intensities of the tetragonal doublets at $\mathrm{t}(002)$ and $\mathrm{t}(200)$. Group IV shows only a monoclinic peak, whereas Group V shows a hump on the left shoulder and less asymmetrical broadening than Groups II and III, but with no decreased intensity of the $\mathrm{t}$ (I II) peak. Equal intensities of the tetragonal doublets at $\mathrm{t}(002)$ and $\mathrm{t}(200)$ in Group V. 

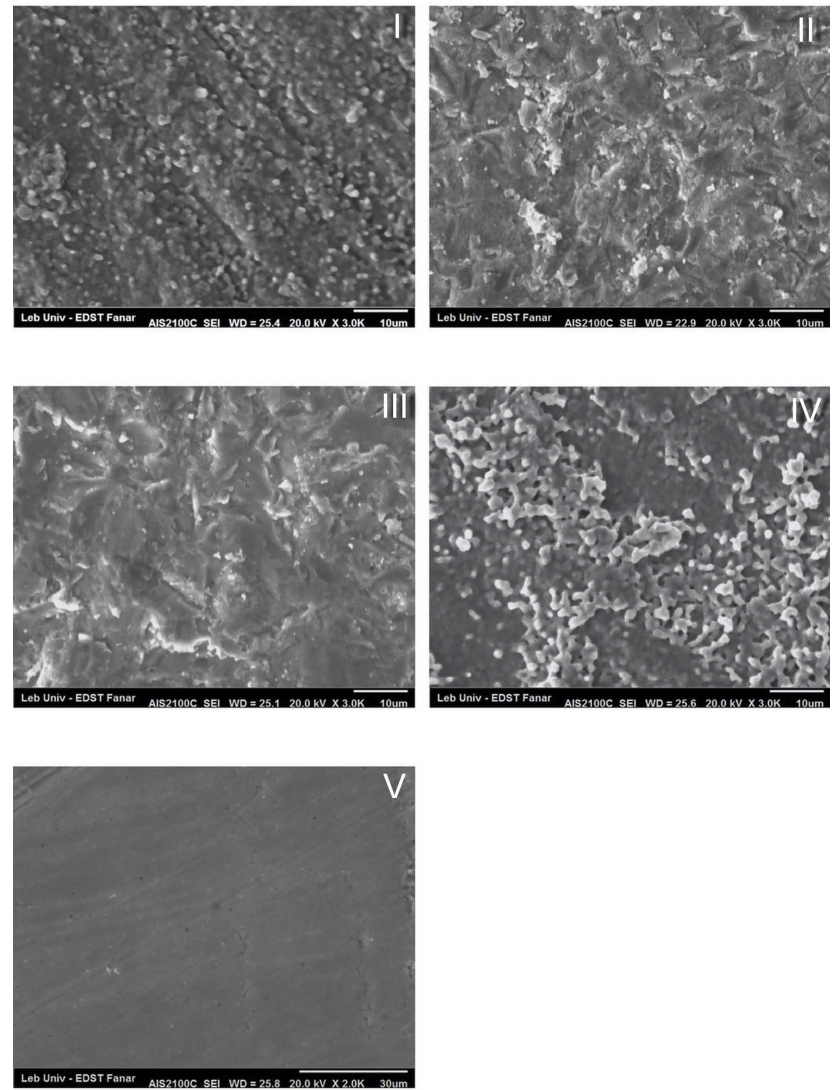

Figure 2 SEM analysis of Groups I, II IIII, IV, and V. Group III appeared with deep grooves and pits with sharp edges. Group II shows a less destructive surface than Group III. Group IV acts as the control. Group V shows the indentation of grit paper.
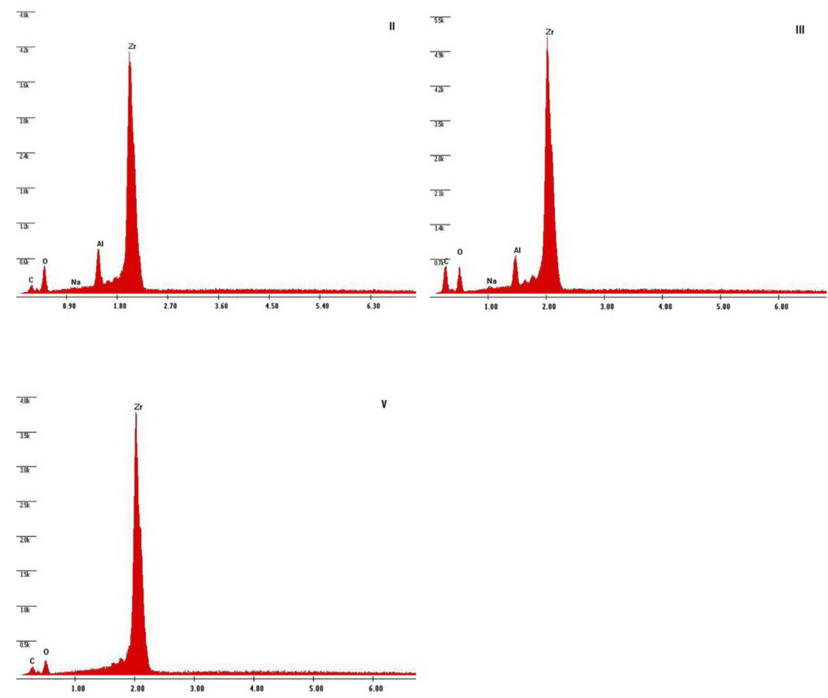

Figure 3 EDX analysis of Groups II, III, and V. EDX analysis of Groups II and III shows the impaction of $\mathrm{Al}_{2} \mathrm{O}_{3}$ particles. In Group $\mathrm{V}$, no silica was retained on SIE surface.

Graphite that is not used before laser treatment could be the reason for the decrease in energy discharge on the zirconia surface, and therefore decrease the destructive effect of the
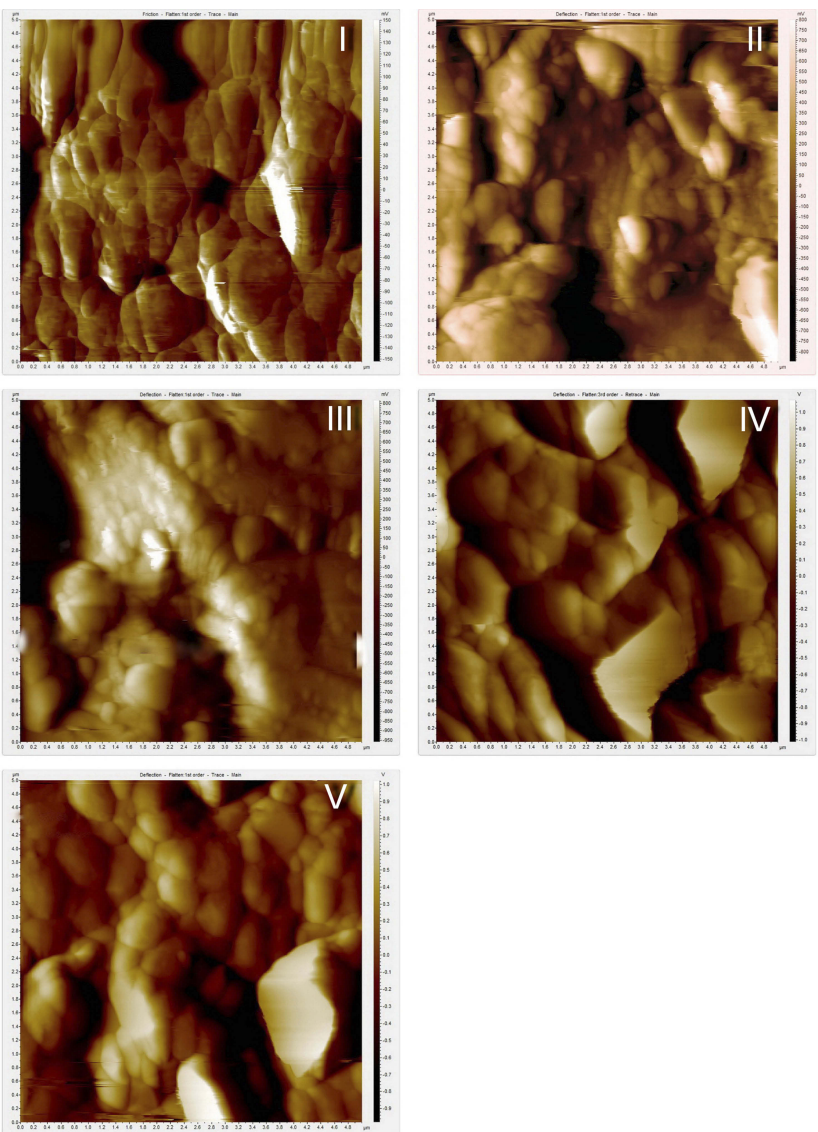

Figure 4 AFM analysis of Groups I, II, III, IV, and V. The grain boundaries are clearly visible in groups I, IV, and V, whereas they were lost in Groups II and III.

laser. Another reason might be the choice of laser energy (5.5 $\mathrm{W})$, which was based on the pilot evaluation done before the performance of this work.

This laboratory study is in agreement with the one published by Sopher et $\mathrm{al}^{38}$ reporting that the use of laser surface treatment by using graphite coating to enhance laser absorption, creating a damaged surface with severe micro-cracks as a result of energy discharge. The study of Stubinger et $\mathrm{al}^{39}$ reported that SEM analysis of Er:YAG and diode lasers caused no visible surface alteration as compared to untreated surfaces, and undesirable effects were noted on zirconia when the $\mathrm{CO}_{2}$ laser was applied, with severe melting and cracking.

The laser treatment induced a significant increase of $\mathrm{Xm} \%$ (4\%) with the control group. However, when the $\mathrm{Xm} \%(4 \%)$ of the laser group was compared to the $\mathrm{Xm}$ $\%$ of the grit-blasted groups $50 \mu \mathrm{m}(8 \%)$ and $110 \mu \mathrm{m}$ $(13 \%)$, and to the SIE group $(3 \%)$, the statistical analysis showed a lower significant $\mathrm{Xm} \%$ with the gritblasted groups and no statistical significance with the SIE group. 
The XRD analysis of the studied groups shows a decrease of the intensities of the $t$ (111) peak of groups abraded with $110 \mu \mathrm{m}$ and $50 \mu \mathrm{m} \quad \mathrm{AL}_{2} \mathrm{O}_{3}$ particles. However, the intensities of $\mathrm{t}$ (111) peak of control, laser and SIE groups were not decreased, since the surface of those groups are free of residual compressive stress. ${ }^{40}$

Moreover, the X-ray diffraction analysis of the studied groups shows asymmetrical broadening of $\mathrm{t}$ (111) peak and an increase of FWHM of AL $50 \mu \mathrm{m}$ and AL $100 \mu \mathrm{m}$ and the SIE groups. Because the same pressure, time, and distance were used in Groups II and III, AL 50 and AL 100 , it appears that the particle size is the decisive factor, but the laser group behaved like the control group.

As well as the reverse intensities of tetragonal doublets, $t(002)$ and $t$ (200) were only observed in Groups II and III, and to a lesser extent in the SIE group. These observations were related to residual compressive stresses due to the type and size of abrasive particles. Given that, other factors that contribute to this broadening are the cubic phase at $c$ (111) in the place of the most intense peak $\mathrm{t}(111)$ and the grains which broke under stress that may exist in the upper surface layer. ${ }^{40,41,42}$

On the other hand, Moon et $\mathrm{al}^{31}$ observed that, when an abrasive particle is pressed against the surface of the monolithic zirconia specimen, a contact stress field is generated.

This may suggest that the parameters used in the laser group did not lead to a surface with residual compressive stress, which is confirmed by SEM image of group V that shows a surface topography similar to the control group, and the AFM images of groups II and III that show a surface lost their grain boundaries.

Ghasemi et $\mathrm{al}^{43}$ studied and suggested that the use of 3 $\mathrm{W}$ power on a zirconia surface enhances the bond strength, but not the surface roughness. Some others ${ }^{44}$ have concluded that a $\mathrm{CO}_{2}$ laser at $4 \mathrm{~W}$ and an Er,Cr:YSGG laser at only $3 \mathrm{~W}$ output power could be regarded as surface treatment options for roughening the zirconia surface.

The surface roughness of Groups III and IV showed a significant increase of the $R_{a}$ value with control, whereas Group V showed a significant decrease of $R_{a}$ value with the control group.

Group II showed no significant increase of the $R_{a}$ value with the control group and a significant decrease with Group III. The reason behind the lower $R_{a}$ value of Group II could be due to the grit-blasting size, time, and/ or pressure, which was only enough to abrade the prominent grains on zirconia surface as a result of sintering process. Whereas grit-blasting with larger $\mathrm{Al}_{2} \mathrm{O}_{3}$ particles in Group III resulted in a surface with big grooves and pits.

The present results accord with a previous study ${ }^{45}$ that concluded that grit-blasting with larger $\mathrm{Al}_{2} \mathrm{O}_{3}$ particle size and time ( $250 \mu \mathrm{m}$ for 30 seconds) resulted in an increase of surface roughness when compared with grit-blasting with a smaller particle size $(30 \mu \mathrm{m}, 50 \mu \mathrm{m}$, and 110 $\mu \mathrm{m})$. Given this, some others ${ }^{34,46,47}$ have found that the extent of morphological changes on the zirconia surface depends on the particle sizes and blasting pressure.

Therefore, we can state that the two responsible factors for the increase in the $R_{a}$ value in Group III are the abrasive grain size and the pressure. Moreover, because the pressure and time used in Groups II and III are the same, we can also state that the time is another responsible factor for increasing surface roughness.

The $R_{a}$ value of Group IV was significantly higher than all other groups. The SEM evaluation of Group IV showed a surface that is approximately similar to the control group, and is free of cracks. In the present study the use of laser energy density of $5.5 \mathrm{~W}$ for 2 minutes was based on a pilot evaluation. ${ }^{48}$ It shows that the laser energy density of $6 \mathrm{~W}$ was destructive, and the laser energy density of $5 \mathrm{~W}$ did not change the surface roughness value.

Our results are in accordance with a previous study, ${ }^{44}$ which used a Er,Cr:YSGG laser with a laser power of 2 and $3 \mathrm{~W}$. It was found that, in laser-treated groups, the surface roughness was much lower than compared with the other groups, However, it was not in agreement with Kirmali et $\mathrm{al}^{48}$ who used Er,Cr:YSGG laser irradiation with different energy intensities (1-6 W) and who found no significant difference of surface roughness between all the intensities that were used. However, the time that was used in their study (20 seconds) could not have been enough to increase the surface roughness.

The lower significance of the $R_{a}$ value of Group V with all other groups might be due to the effect of polishing by grit papers before the application of a glass layer. ${ }^{5}$

Several studies reported that the abrasive grain size (25 $\mu \mathrm{m}, 50 \mu \mathrm{m}$, or $110 \mu \mathrm{m}$ ) has no effect on micromechanical retention, despite the difference in surface roughness created. $^{46-49}$ On the other hand, some others have observed enhancement of adhesion strength with resin cement, leading to a smoother surface produced after air abrasion with $50 \mu \mathrm{m} \mathrm{Al}_{2} \mathrm{O}_{3}$ particles. ${ }^{51,52}$

In the present study all study groups showed a significant increase in bond strength when compared to the 
control group, despite having differences in surface roughness values, but there was no significant difference of shear bond strength value between them. It appeared from those results that the surface roughness is not the only factor affecting the increase in adhesion strength, despite it enhancing the surface for better wettability and increasing the bonding surface area.

The use of Clearfil ${ }^{\mathrm{TM}}$ ceramic primer that contains the MDP monomer with Panavia ${ }^{\mathrm{TM}}$ resin composite cement aimed to increase the chemical interaction of 10-MDP with the zirconia surface. A previous study $^{53}$ reported that, even if the resin cement includes MDP, its functional monomer properties in terms of the amount and flow seemed insufficient to increase the Y-TZP adhesion without any pretreatment.

Chen et $\mathrm{al}^{54}$ observed that there was a direct chemical bond between the phosphate ester group and the oxides on the zirconia surface, and Nagaoka et $\mathrm{a}^{55}$ found that adhesion between 10-MDP and zirconia was not only ionic bonding, but also hydrogen bonding. Inokoshi et al ${ }^{19}$ concluded that the combination of mechanical and chemical pre-treatment appeared particularly crucial to obtain durable bonding to zirconia ceramics, and a recent study from Skienhe et $\mathrm{al}^{40}$ concluded that the combination of micromechanical and chemical surface treatment is a prerequisite for increasing the adhesion with zirconia ceramics. A previous study concluded that a reliable and durable resin zirconia bonding is vital for the longevity of dental restoration. ${ }^{56}$

Therefore, the second factor that increases the adhesion strength significantly is the adhesive system used. Given this, our results are in agreement with many studies showing that the primer that contain MDP monomer should be used with resin cement, even if it contains this monomer. ${ }^{57-59}$

In contrast, Cavalcanti et al ${ }^{60}$ claimed that sandblasting appears to be a more efficient method to modify zirconia surfaces compared with laser irradiation, and the use of MDP-containing primers improved bond strength without previous mechanical or laser surface treatment.

Clinically speaking, the success of an adhesive bond to zirconia depends on different factors. One of the factors that leads to the loss of primary stability of zirconia to resin cement is the transformation from the tetragonal into the monoclinic phase due to the increase in temperature and the presence of moisture. ${ }^{61,62}$ Moreover, the crack growth by the degradation mechanism of zirconia in water has a direct association with the failure of restorations. ${ }^{20,21}$
In contrast, Amaral et a ${ }^{63}$ reported that any amount of monoclinic phase due to grit-blasting apparently hindered the progression of low temperature degradation, and others stated that the transformation toughening as a result of $t-m$ phase transformation may decrease the detrimental effects of aging on the specimens, ${ }^{18,19}$

We have used the shear bond strength test for adhesion strength measurement because it is simple and less technique-sensitive, but it has some shortcomings in which the stresses are not homogeneous across the interface. ${ }^{64,65}$ Despite that, it can be described as a practical measurement to test the bond strength of cements to hard materials such as ceramics.

The different published results regarding zirconia surfaces can be attributed to many variables, such as the different laser settings and types, different cements, and different abrasive parameters or varying methodology used. ${ }^{16,24}$

The use of Er,Cr:YSGG and grit-blasting appeared to be a surface treatment method that enhanced the adhesion strength of MDP containing resin composite cement to zirconia.

\section{Conclusions}

The following conclusions can be drawn:

1. The $t-m$ phase transformation is directly related to abrasive particles size.

2. Grit-blasting with $50 \mu \mathrm{m} \mathrm{Al} \mathrm{O}_{3}$ induced a lower t-m phase transformation than $100 \mu \mathrm{m}$ and it seems to be a feasible surface treatment method.

3. The use of a Er,Cr:YSGG laser for zirconia surface treatment with adjusted parameters appeared to be useful as a non-destructive surface treatment method.

4. The use of MDP-containing primers with resin composite cement containing the MDP monomer is required to enhance the bonding efficiency.

\section{Disclosure}

The authors report no conflicts of interest in this work.

\section{References}

1. Li RW, Chow TW, Matinlinna JP. Ceramic dental biomaterials and CAD/CAM technology: state of the art. J Prosthodont Res. 2014;58 (4):208-216. doi:10.1016/j.jpor.2014.07.003

2. Miyazaki T, Nakamura T, Matsumura H, Ban S, Kobayashi T. Current status of zirconia restoration. J Prosthodont Res. 2013;57(4):236-261. doi:10.1016/j.jpor.2013.09.001 
3. Raigrodski AJ, Hillstead MB, Meng GK, Chung KH. Survival and complication of zirconia -based fixed dental prostheses. J Prosthet Dent. 2012;107(3):170-177. doi:10.1016/S0022-3913(12)60051-1

4. Özcan M, Bernasconi M. Adhesion to zirconia used for dental restorations: a systematic review and meta-analysis. $J$ Adhes Dent. 2015;17(1):7-26.

5. Aboushelib MN, Kleverlaan CJ, Feilzer AJ. Selective infiltration etching for a strong and a durable bonding with zirconia-based restorations. J Prosthet Dent. 2007;98(5):379-388. doi:10.1016/ S0022-3913(07)60123-1

6. Liu D, Matinlinna JP, Tsoi JK, et al. A new modified laser pretreatment for porcelain zirconia bonding. Dent Mater. 2013;29(5):559565. doi:10.1016/j.dental.2013.03.002

7. Ozcan M, Raadschelders J, Vallittu P, et al. Effect of particle deposition parameters on silica- coating of zirconia using a chairside airabrasion device. J Adhes Dent. 2013;15(3):211-214. doi:10.3290/j. jad.a29536

8. May LG, Passos SP, Capelli DB, Özcan M, Bottino MA, Valandro LF. Effect of silica coating combined to a MDP-based primer on the resin bond to Y-TZP ceramic. J Biomed Mater Res B. 2010;95B:6974. doi: $10.1002 / \mathrm{jbm} . b .31684$

9. Lung CYK, Matinlinna JP. Aspects of silane coupling agents and surface conditioning in dentistry: an overview. Dent Mater. 2012;28 (5):467-477. doi:10.1016/j.dental.2012.02.009

10. Matinlinna JP, Lung CYK, Tsoi JKH. Silane adhesion mechanism in dental applications and surface treatments: a review. Dent Mater. 2018;34(1):13-28. doi:10.1016/j.dental.2017.09.002

11. Inokoshi M, De Munck J, Minakuchi S, Van Meerbeek B. Metaanalysis of bonding effectiveness to zirconia ceramics. J Dent Res. 2014;93(4):329-334. doi:10.1177/0022034514524228

12. Lung CY, Botelho MG, Heinonen M, Matinlinna JP. Resin zirconia bonding promotion with some novel coupling agents. Dent Mater. 2012;28(8):863-872. doi:10.1016/j.dental.2012.04.023

13. Ahn JS, Yi YA, Lee Y, Seo DG. Shear bond strength of MDPcontaining self-adhesive resin cement and Y-TZP ceramics: effect of phosphate monomer-containing primers. Biomed Res Int. 2015. doi: 10.1155

14. Pott PC, Stiesch M, Eisenburger M. Influence of 10-MDP adhesive system on shear bond strength of zirconia-composite interfaces. $J$ Dent Mater Tec. 2015;4(3):117-126.

15. Pott PC, Stiesch M, Eisenburger M. Influence of artificial aging on the shear bond strength of zirconia-composite interfaces after pretreatment with new 10-MDP adhesive systems. J Dent Mater Tech. 2016;5(1):1-9.

16. Aurelio IL, Marchionatti AME, Montagner AF, May LG, Soares FZM. "Does air particle abrasion affect the flexural strength and phase transformation of Y-TZP? A systematic review and meta-analysis. Dent Mater. 2016;32(6):827-845. doi:10.1016/j.dental.2016. 05.005

17. Amaral M, Cesar P, Lohbauer U, Valandro L. Fatigue behavior of YTZP ceramic after surface treatments. J Mech Behav Biomed Mater. 2016;57:149-156. doi:10.1016/j.jmbbm.2015.11.042

18. Kim J-W, Covel NS, Guess PC, Rekow ED, Zhang Y. Concerns of hydrothermal degradation in CAD/CAM Zirconia. $J$ Dent Res. 2010;89(1):91-95. doi:10.1177/0022034510366903

19. Inokoshi M, Vanmeensel K, Zhang F, et al. Aging resistance of surface-treated dental zirconia. Dent Mater. 2015;31(2):182-194. doi:10.1016/j.dental.2014.11.018

20. Denry I, Kelly JR. State of the art of zirconia for dental applications. Dent Mater. 2008;24(3):299-307. doi:10.1016/j.dental.2007.05.007

21. Chevalier J. What future for zirconia as a biomaterial? Biomaterials. 2006;27(4):535-543. doi:10.1016/j.biomaterials.2005.07.034

22. El Gamal A, Medioni E, Rocca JP, Fornaini C, Muhammad OH, Brulat-Bouchard N. Shear bond, wettability and AFM evaluations on $\mathrm{CO}(2)$ laser-irradiated $\mathrm{CAD} / \mathrm{CAM}$ ceramic surfaces. Lasers Med Sci. 2017;23(4):779-785. doi:10.1007/s10103-017-2171-4
23. Paranhos MP, Burnett LH Jr, Magne P. Effect Of Nd: YAGlaser and $\mathrm{CO} 2$ laser treatment on the resin bond strength to zirconia ceramic. Quintessence Int. 2011;42(1):79-89.

24. GarcõÂa-Sanz V, Paredes-Gallardo V, Mendoza-Yero O, et al. The effects of lasers on bond strength to ceramic materials: a systematic review and meta-analysis. PLoS One. 2018;13:e0190736. doi:10.1371/journal.pone. 0190736

25. Cristoforides P, Amaral R, May LG, Bottino MA, Valandro LF. Composite resin to yttria stabilized tetragonal zirconia polycrystal bonding: comparison of repair methods. Oper Dent. 2012;37:263271. doi:10.2341/11-193-L

26. Nahas P, Zeinoun T, Namour M, Ayach T, Nammour S. Effect of Er: YAGlaser energy densities on thermally affected dentin layer: morphological study. Laser Ther. 2018;27(2):91-97. doi:10.5978/islsm.18-OR-07

27. Garvie RC, Nicholson PS. Phase analysis in zirconia systems. $J$ Am Ceram Soc. 1972;55(6):303-305. doi:10.1111/jace.1972.55.issue-6

28. Toraya H, Masahiro M, Somiya S. Calibration curve for quantitative analysis of the monoclinic-tetragonal $\mathrm{ZrO} 2$ system by $\mathrm{X}$-ray diffraction. J Am Ceram Soc. 1984;67(6):119-121.

29. Anstis GR, Chantikul P, Lawn BR, Marshall DB. A critical evaluation of indentation techniques for measuring fracture toughness: I, direct crack measurements. J Am Ceram Soc. 1981;64(9):533-538. doi:10.1111/jace.1981.64.issue-9

30. Kosmac T, Oblak C, Jevnikar P, Funduk N, Marion L. The effect of surface grinding and sandblasting on flexural strength and reliability of Y-TZP zirconia ceramic. Dent Mater. 1999;15(6):426-433. doi:10.1016/S0109-5641(99)00070-6

31. Ozcan M, Vallittu PK. Effect of surface conditioning methods on the bond strength of luting cement to ceramics. Dent Mater. 2003;19 (8):725-731. doi:10.1016/S0109-5641(03)00019-8

32. Moon JE, Kim SH, Lee JB, Han JS, Yeo IS, Ha SR. Effects of airborne particle abrasion protocol choice on the surface characteristics of monolithic zirconia materials and the shear bond strength of resin cement. Ceram Int. 2016;42(1):1552-1562. doi:10.1016/j.ceramint.2015.09.104

33. Zhang Y, Lawn BR, Malament KA, Van Thompson P, Rekow ED. Damage accumulation and fatigue life of particle-abraded ceramics. Int J Prosthodont. 2006;19(5):442-448.

34. Hallmann L, Ulmer P, Reusser E, Hämmerle CHF. Effect of blasting pressure, abrasive particle size and grade on phase transformation and morphological change of dental zirconia surface. Surf Coat Tech. 2012;206(19-20):4293-4302. doi:10.1016/j.surfcoat.2012.04.043

35. Chintapalli RK, Marro FG, Jimenez-Pique E, Anglada M. Phase transformation and subsurface damage in 3YTZP after sandblasting. Dent Mater. 2013;29(5):566-572. doi:10.1016/j.dental.2013.03.005

36. Özcan M, Melo RM, Souza RO, Machado JP, Felipe VL, Bottino MA. Effect of air-particle abrasion protocols on the biaxial flexural strength, surface characteristics and phase transformation of zirconia after cyclic loading. J Mech Behav Biomed Mater. 2013;20:19-28. doi:10.1016/j.jmbbm.2013.01.005

37. Hao L, Lawrence J. Effects of Nd: yAGlaser treatment on the wettability characteristics of a zirconia-based bioceramic. Opt Lasers Eng. 2006;44(8):803-814. doi:10.1016/j.optlaseng.2005.08.001

38. Spohr A, Borges G, Burnett L, Goncalves E, Silva H. Surface modification of in-ceram zirconia ceramic by ND: YAG laser, rocatec system, or aluminum oxide sandblasting and its bond strength to a resin cement. Photomed Laser Surg. 2008;26(3):203-208. doi:10. 1089/pho.2007.2130

39. Stubinger S, Homann F, Etter C, Miskiewicz M, Wieland M, Sader R. Effect of Er: YAG,CO2 and diode laser irradiation on surface properties of zirconia endosseous dental implants. Lasers Surg Med. 2008;40(3):223-228. doi:10.1002/lsm.20614

40. Skienhe H, Habchi R, Ounsi H, Ferrari M, Salameh Z. Evaluation of the effect of different types of abrasive surface treatment before and after zirconia sintering on its structural composition and bond strength with resin cement. Biomed Res Int. 2018;2018:12 Article ID 1803425. doi:10.1155/2018/1803425. 
41. Leng Y. Materials Characterization: Introduction to Microscopic and Spectroscopic Methods. Germany: Wiley; 2013.

42. Kontoyannis CG, Orkoula M. Quantitative determination of the cubic, tetragonal and monoclinic phases in partially stabilized zirconia by Raman spectroscopy. J Mater Sci. 1994;29(20):5316-5320. doi:10.1007/BF01171541

43. Ghasemi A, Kermanshah H, Ghavam M, et al. Effect of Er, Cr: YSGG laser treatment on microshear bond strength of zirconia to resin cement before and after sintering. J Adhes Dent. 2014;16 (4):377-382. doi:10.3290/j.jad.a32444

44. Akhavan Zanjani V, Ahmadi H, Nateghifard A, et al. Effect of different laser surface treatment on microshear bond strength between zirconia ceramic and resin cement. J Investig Clin Dent. 2015;6 (4):294-300. doi:10.1111/jicd.12105

45. Turp V, Sen D, Tuncelli B, Goller G, Ozcan M. Evaluation of air-particle abrasion of Y-TZP with different particles using microstructural analysis. Aust Dent J. 2013;58(2):183-191. doi:10.1111/adj.12065

46. Gomes AL, Castillo OR, Lynch CD, Montero J, Albaladejo A. Influence of sandblasting granulometry and resin cement composition on microtensile bond strength to zirconia ceramic for dental prosthetic frameworks. J Dent. 2013;41(1):31-41. doi:10.1016/j.jdent.2012.09.013

47. Hallmann L, Ulmer P, Lehmann F, et al. Effect of surface modifications on the bond strength of zirconia ceramic with resin cement. Dent Mater. 2016;32(5):631-639. doi:10.1016/j.dental.2016.02.001

48. Kirmali O, Kustarci A, Kapdan A, Er K. Efficacy of surface roughness and bond strength of Y-TZP zirconia after various PreTreatments. Photomed Laser Surg. 2015;33(1):15-21. doi:10.1089/ pho.2014.3825

49. Tzanakakis EG, Zoutzas T, Koidis PT, Zoutzas T, Koidis PT. Is there a potential for durable bond to zirconia restoration? A systematic review. J Prosthet Dent. 2016;115(1):9-19. doi:10.1016/j. prosdent.2015.09.020

50. Ozcan M, Nijhuis H, Valandro LF. Effect of various surface conditioning methods on the adhesion of dual-cure resin cement with MDP functional monomer to zirconia after thermal aging. Dent Mater. 2008;27(1):99-104. doi:10.4012/dmj.27.99

51. Blatz MB, Phark J-H, Ozer F, et al. In vitro comparative bond strength of contemporary self-adhesive resin cements to zirconium oxide ceramic with and without air-particle abrasion. Clin Oral Investig. 2010;14(2):187-192. doi:10.1007/s00784-009-0278-0

52. Xie ZG, Meng XF, Xu LN, Yoshida K, Luo XP, Gu N. Effect of air abrasion and dye on the surface element ratio and resin bond of zirconia ceramic. Biomed Mater. 2011;6(6):1-7. doi:10.1088/1748$6041 / 6 / 6 / 065004$
53. Yi YA, Ahn JS, Park YJ, et al. The effect of sandblasting and different primers on shear bond strength between Yttria tetragonal zirconia polycrystal ceramic and a self-adhesive resin cement. Operat Dent. 2015;40(1):63-71. doi:10.2341/13-149-L

54. Chen C, Xie H, Song X, Burrow MF, Chen G, Zhang F. Evaluation of a commercial primer for bonding of zirconia to two different resin composite cements. J Adhes Dent. 2014;16(2):169-176.

55. Nagaoka N, Yoshihara K, Feitosa VP, et al. Chemical interaction mechanism of 10-MDP with zirconia. Sci Rep. 2017;7. Article ID 45563. doi:10.1038/srep45563

56. Liu D, Pow EHN, Tsoi JKH, Matinlinna JP. Evaluation of four surface coating treatments for resin to zirconia bonding. JMechan Behav Biomed Mater. 2014;32:300-309. doi:10.1016/j.jmbbm.2013.12.011

57. Shin YJ, Shin Y, Yi YA, et al. Evaluation of the shear bond strength of resin cement to Y-TZP ceramic after different surface treatments. Scanning. 2014;36(5):479-486. doi:10.1002/sca.2 1142

58. Koizumi H, Nakayama D, Komine F, Blatz MB, Matsumura H. Bonding of resin-based luting cements to zirconia with and without the use of ceramic priming agents. J Adhes Dent. 2012;14(4):385-392.

59. Nakayama D, Koizumi H, Komine F, Blatz MB, Tanoue N, Matsumura $\mathrm{H}$. Adhesive bonding of zirconia with single liquid acidic primers and a tri-n-butylborane initiated acrylic resin. $J$ Adhes Dent. 2010;12(4):305-310.

60. Cavalcanti AN, Foxton RM, Watson TF, Oliveira MT, Giannini M, Marchi GM. Bond strength of resin cements to a zirconia ceramic with different surface treatments. Oper Dent. 2009;34(3):280-287. doi: $10.2341 / 08-80$

61. Kawai Y, Uo M, Wang Y, Kono S, Ohnuki S, Watari F. Phase transformation of zirconia ceramics by hydrothermal degradation. Dent Mater J. 2011;30(3):286-292.

62. Nakamura T, Usami H, Ohnishi H, et al. The effect of adding silica to zirconia to counteract zirconia's tendency to degrade at low temperatures. Dent Mater J. 2011;30(3):330-335.

63. Amaral M, Valandro LF, Bottino MA, Souza RO. Low temperature degradation of a Y-TZP ceramic after surface treatments. J Biomed Mater Res B Appl Biomater. 2013;101(8):1387-1392. doi:10.1002/ jbm.b.32957

64. Brag RR, Meira JB, Boaro LC, Xavier TA. Adhesion to tooth structures: a critical review of macro test methods. Dent Mater. 2010;26 (2):38-49. doi:10.1016/j.dental.2009.11.150

65. Sirisha K, Rambabu T, Shankar YR, Ravikumar P. Validity of bond strength tests: a critical review: part I. J Conserv Dent. 2014;17 (5):305. doi:10.4103/0972-0707.136340
Clinical, Cosmetic and Investigational Dentistry

\section{Publish your work in this journal}

Clinical, Cosmetic and Investigational Dentistry is an international, peer-reviewed, open access, online journal focusing on the lates clinical and experimental research in dentistry with specific emphasis on cosmetic interventions. Innovative developments in dental materials, techniques and devices that improve outcomes and patien satisfaction and preference will be highlighted. The manuscript management system is completely online and includes a very quick and fair peer-review system, which is all easy to use. Visit http://www.dovepress.com/testimonials.php to read real quotes from published authors. 